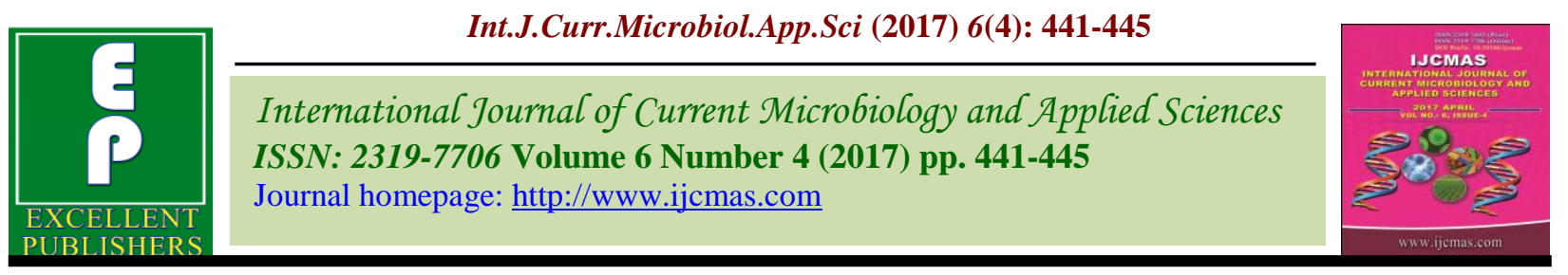

Original Research Article

https://doi.org/10.20546/ijcmas.2017.604.050

\title{
Variability in Epicuticular Wax Content among Temperate Maize Lines as a Drought Tolerance Related Mechanism
}

\author{
Z.A. Dar ${ }^{1 *}$, A.A. Lone ${ }^{1}$, M.D. Pratibha ${ }^{2}$, P.A. Sofi ${ }^{2}$, I. Abidi ${ }^{2}$, \\ G. Ali ${ }^{2}$, M.A. Wani ${ }^{2}$ and J.A. Khan ${ }^{2}$ \\ ${ }^{1}$ DARS, Budgam(SKUAST-K), India \\ ${ }^{2} \mathrm{UAS}$, Bangalore, India \\ *Corresponding author
}

\section{A B S T R A C T}

Keywords

Maize, Epicuticular

Wax content,

Genotype, Inbreds.

Article Info

Accepted:

02 March 2017

Available Online:

10 April 2017
Thirty genotypes of Maize which included twenty eight inbred lines and two checks maintained at $\mathrm{D}(\mathrm{K}) \mathrm{ARS}$, SKUAST-K were used for the study carried out in the Department of Crop Physiology, University of Agricultural Sciences, GKVK Bangalore. In this programme the genetic variability for Epicuticular Wax Content (EWC) was studied. The data of the experiment revealed a significant genetic variability in epicuticular waxes among the germplasm lines of maize. Accordingly, the EWC ranged from 1.56 (KDM-921A) $\mu \mathrm{g} / \mathrm{cm}^{2}$ to 7.54 (KDM-954) $\mu \mathrm{g} / \mathrm{cm}^{2}$ with a mean of $4.25 \mu \mathrm{g} / \mathrm{cm}^{2}$.The frequency distribution also indicated the spread of genotypes across the mean to suggest the existence of an appreciable genetic variability for EWC in maize genotypes

\section{Introduction}

Maize or Corn (Zea mays) is a plant belonging to the family of grasses (Poaceae). It is cultivated globally and is one of the most important cereals. Maize grains have long been used as feed, food consumption and industrial applications. India has $5 \%$ of maize acreage and contributes $2 \%$ of world production. Maize occupies an important place in Indian Agriculture. It is the third most important cereal in India after wheat and rice. The major maize growing states are Uttar Pradesh, Bihar, Rajasthan, Madhya Pradesh, Punjab, Andhra Pradesh, Himachal Pradesh, West Bengal, Karnataka and Jammu and Kashmir, jointly accounting for over $95 \%$ of the national maize production. In India, about $28 \%$ of maize produced is used for food purpose, about $11 \%$ as livestock feed, $48 \%$ as poultry feed, $12 \%$ in wet milling industry (starch and oil production) and $1 \%$ as seed. In the last one decade, it has registered the highest growth rate among all food grains including wheat and rice because of intervention of single cross heterotic hybrids.

According to advance estimates in India (Anonymous, 2015), Maize was cultivated in $9.1 \mathrm{~m}$ ha with a production and productivity of 23.66 (MT) and 26.02 (Q/ha). It contributes nearly $9 \%$ in the national food basket and more than 100 billion to the agricultural GDP at current prices apart from 
the generating employment to over 120 million man-days at the field and downstream agricultural and industrial sectors. In addition to staple food for human being and quality feed and fodder for animals, maize serves as a basic raw material as an ingredient to thousands of industrial products that includes starch, oil, protein, beverages, food sweeteners, pharmaceutical, cosmetic, film, textile, gum, package and paper industries etc.

Drought is a complex syndrome involving timing, intensity, and duration of water deficit; the high variability of these factors makes it difficult to define plant traits required for improved performance under all possible drought situations (Rao and Cramer, 2003). With the unpredictability of drought, geographical and seasonal, including ongoing climate changes, the destructive impact of drought is likely to further increase (Ribautet al., 2004; Banziger and Araus, 2007). Therefore, crop improvement for limitedwater condition is a priority for plant breeding programs worldwide. With most maize in the developing world being grown under rain-fed conditions and the proportion of maize grown in marginal areas increasing, breeding for tolerance to drought has therefore, become a major focus.

\section{Materials and Methods}

The material used for the present study consisted of 28 inbred lines and two checks (GM-6 and CML-442) maintained at Dryland (Karewa) Agriculture Research Station, Budgam (SKUAST-K) (Table 1). Plants were raised in specially constructed root structures that measured $150 \mathrm{~cm}$ tall, $300 \mathrm{~cm}$ wide and $1800 \mathrm{~cm}$ long. An additional $150 \mathrm{~cm}$ tall wall was built in the middle of the structure all along the length to make two halves each 150 $\mathrm{cm}$ wide. Top soil dug out from another field was transported to fill these structures. Soil was compacted to mimic the real field conditions. Seedlings were transplanted in a randomized block design (RBD) with three replications. Plant population was maintained with $60 \times 20 \mathrm{~cm}$ spacing, which ensured that plants experienced the inter-plant competition as in field conditions thus leading to more realistic phenotypic expression. The soils in the GKVK campus had been previously estimated to hold 23 percent water (W/W) at 100 percent field capacity. On an average, surface irrigation was provided once every 5 7 days to bring the soil to 100 percent FC.

As a prerequisite towards quantifying plant waxes, standard graph has to be developed. A colorimetric based assay was followed for wax estimation (Ebercon et al., 1979). The principle behind this assay is the color change brought about by the reaction of acid dichromate with wax. Wax reagent was prepared by mixing $20 \mathrm{~g}$ of potassium dichromate with $40 \mathrm{ml}$ of deionized water. The resulting slurry was then mixed with $1 \mathrm{lt}$ of concentrated $\mathrm{H}_{2} \mathrm{SO}_{4}$ and incubated in a water bath until a clear solution was formed. A wax standard graph was developed using Carnauba wax, which is a plant wax from an Egyptian palm tree. Carnauba wax of 0.5 to $5 \mathrm{mg}$ was used to develop the standard graph.To all these samples, $5 \mathrm{ml}$ of wax reagent was added and boiled for 30 minutes and cooled down afterwards. To this, $12 \mathrm{ml}$ of deionised water was added and allowed for colour development. After the colour development, the samples were filtered using the filter paper and OD was read at $590 \mathrm{~nm}$ using spectrophotometer.

\section{Results and Discussion}

Sufficient amount of genotypic variability for the trait of interest must be available among the genotypes for subsequent use in crop improvement programme. Therefore in the present study, attempts were made to look for genotypic variability for epicuticular wax content in maize inbred lines. A set of 28 inbred lines and 2 checks were selected and 
phenotyped in the present study for the variability in epicuticular wax content (EWC). Using carnauba wax, which is extracted from the leaves of Copernicia prunifera, a standard curve was developed. Following the standard protocol, carnuba wax standards were prepared and OD was read at
$592 \mathrm{~nm}$ and a standard curve with a regression value $\left(\mathrm{R}^{2}\right)$ of 0.987 was developed. Following the standardized protocol to extract epicuticular waxes in rice, the EWC was quantified in all the 30 genotypes of maize.

Table.1 List of inbreds and checks used in the study

\begin{tabular}{|c|c|}
\hline S.No & Accessions \\
\hline 1. & KDM 927A \\
\hline 2. & KDM 930A \\
\hline 3. & KDM 332A \\
\hline 4. & KDM 921A \\
\hline 5. & KDM 408 \\
\hline 6. & KDM 1156 \\
\hline 7. & KDM 941A \\
\hline 8. & KDM 932A \\
\hline 9. & NGB17094-1 \\
\hline 10. & KDM 892A \\
\hline 11. & KDM 362A \\
\hline 12. & NGB 17099-1 \\
\hline 13. & KDM 895A \\
\hline 14. & KDM 1095 \\
\hline 15. & KDM 343A \\
\hline 16. & KDM 329 \\
\hline 17. & KDM 945 \\
\hline 18. & KDM 963A \\
\hline 19. & KDM 925B \\
\hline 20. & KDM 440A \\
\hline 21. & KDM 926B \\
\hline 22. & NGB 17097-1 \\
\hline 23. & KDM 954 \\
\hline 24. & KDM 913A \\
\hline 25. & KDM 443 \\
\hline 26. & KDM 918A \\
\hline 27. & KDM 944A \\
\hline 28. & NGB13905 \\
\hline 29. & GM-6 (C) \\
\hline 30. & CML-442 (C) \\
\hline
\end{tabular}


Fig.1 Genetic variability in EWC in maize genotypes

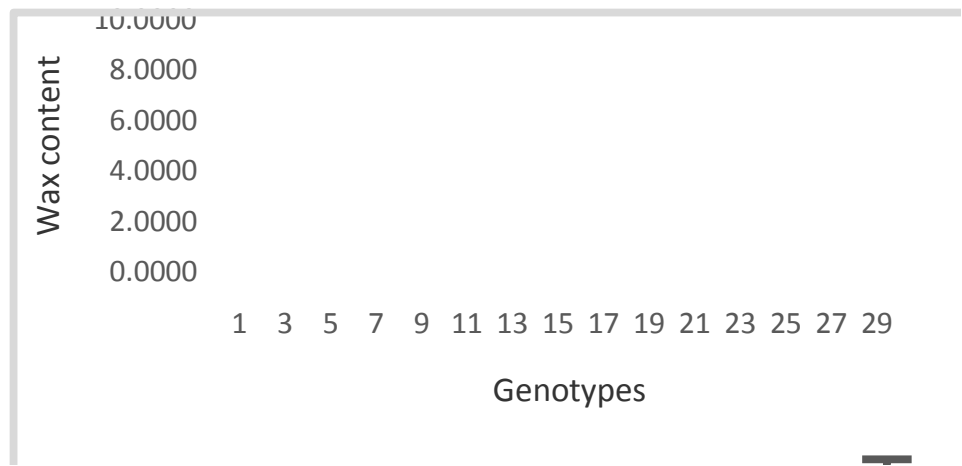

Fig.2 Frequency distribution of EWC in maize genotypes

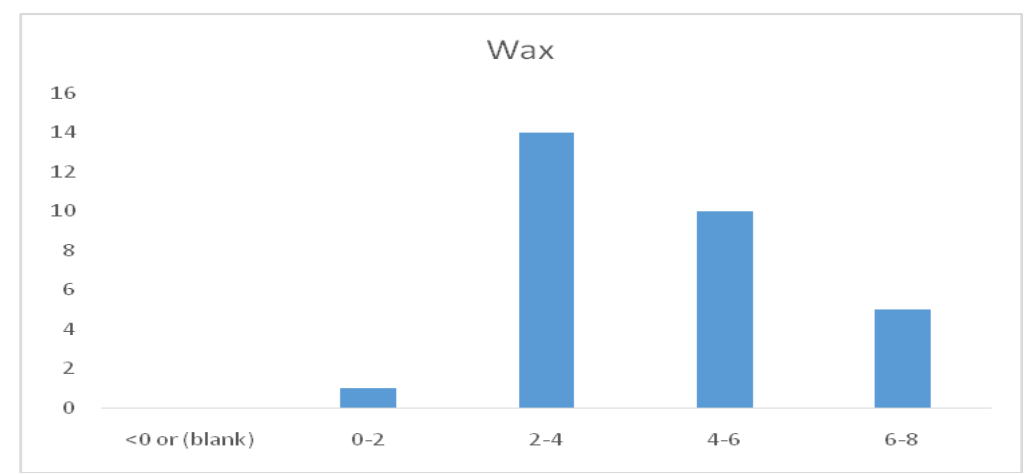

The data of the experiment revealed a significant genetic variability in epicuticular waxes among the germplasm lines of maize (Fig. 1). Accordingly, the EWC ranged from 1.56 (KDM-921A) $\mu \mathrm{g} / \mathrm{cm}^{2}$ to 7.54 (KDM954) $\mu \mathrm{g} / \mathrm{cm}^{2}$ with a mean of $4.25 \mu \mathrm{g} / \mathrm{cm}^{2}$.The frequency distribution also indicated the spread of genotypes across the mean to suggest the existence of an appreciable genetic variability for EWC in maize genotypes (Fig. 2).

A simple colorimetric method of extracting waxes from the chloroform and assessing the chromophore developed by waxes with appropriate reagent was developed to assess the genetic variability in epicuticular wax content. A procedure of dipping the leaves in chloroform for exactly 15 seconds was standardized. Dipping the leaves for more than 15 seconds leads to the dissolution of cuticular and membrane waxes besides the epicuticular waxes. This protocol was adopted to assess the EWC among 86 genotypes which were selected based on the difference in rate of water loss (RWL) measured in the previous experiment. Such standardization is required in the species where EWC is to be determined. While characterizing mulberry accessions for EWC, Mamrutha (2008) standardized a dipping time of 15 seconds to extract epicuticular waxes. Therefore it appears that, depending on the species, dipping duration also varies and accordingly, needs standardization of extraction protocol.

In the present study with maize inbred lines, a significant genetic variability was noticed for EWC which ranged from 1.56 to $7.54 \mu \mathrm{g} / \mathrm{cm}^{2}$. Significant genetic variability for EWC was also noticed by Mamrutha (2008) and Mamrutha et al., (2010) in mulberry where 
they have showed that, the EWC of mulberry accessions remained stable across seasons and locations. All these evidences therefore clearly emphasize the need for including epicuticular wax content as a trait in a breeding program to enhance the water conservation.

In conclusion the promising lines identified like KDM-954 for epicuticular wax content can be used as trait donor lines to transfer specific traits in to a recipient genotype. The contrasting lines will be useful in developing trait specific mapping populations as well as for greater understanding of molecular regulation of the trait.

\section{References}

Anonymous. 2015. Economic Survey of India(2014-15), Ministry of Finance, Govt of India, PP 16-19.

Banziger, M. and Araus, J.L. 2007. Recent advances in breeding maize for drought and salinity stress tolerance, p. 587-601, In M.A. Jenks, P.M. Hasegawa, and S. M. Jain (eds) Adv. Mol. Breeding Towards Drought and Salt Tolerant Crops.

Ebercon, A., Blum, A. and Jordan, W.R. 1979. A rapid colorometric method for epicuticular wax content of sorghum leaves. Crop Sci., 17: 179-180.

Mamrutha, H.M. 2008. Cloning and characterization of epicuticular wax synthesising genes from mulberry (Morus alba l.): a potential option to reduce transpiration and postharvest water loss. PhD thesis submitted to Dept. of Crop Physiology, University of Agricultural Sciences, Bangalore-65.

Mamrutha, H.M., Mogili, T., Lakshmi, K.J., Rama, N., Kosma, D., Udayakumar, M., Jenks, M.A. and Nataraja, K.N. 2010. Leaf cuticular wax amount and crystal morphology regulate post-harvest water loss in mulberry (Morus species). Plant Physiol. Biochem., 48(8): 690-696.

Rao, I., and Cramer. G. 2003. Plant nutrition and crop improvement in adverse soil conditions, p.270-303, In M. Chrispeels and D. Sadava (ed). Plants, Genes, and Crop Biotechnol.

Ribaut, J.M., Hoisington, D.A., Bänziger, M., Setter, T.L., and Edmeades, G.O. 2004. Genetic dissection of drought tolerance in maize, A case study, p. 571-609, In H.T. Nguyen and A. Blum (eds) Physiol. Biotechnol. Integration For Plant Breeding.

\section{How to cite this article:}

Dar, Z.A., A.A. Lone, M.D. Pratibha, P.A. Sofi, I. Abidi, G. Ali, M.A. Wani and Khan, J.A. 2017. Variability in Epicuticular Wax Content among Temperate Maize Lines as a Drought Tolerance Related Mechanism. Int.J.Curr.Microbiol.App.Sci. 6(4): 441-445. doi: https://doi.org/10.20546/ijcmas.2017.604.050 